\title{
Application of Speech Range Profile in Hindi in Hyperfunctional Voice Disorders: A Case-controlled Observational Study
}

\author{
Noorain Alam ${ }^{1}$, Sanjay Munjal ${ }^{2}$, Raj Kumar ${ }^{3}$, Diya Nair $^{4}$, Naresh Panda ${ }^{5}$
}

\begin{abstract}
Background: Speech range profile (SRP) is defined as the graphical plot of an individual's frequency-intensity interactions occurring during connected speech production. As speech stimuli are better method to assess the functional limit of voice, SRP has advantage over voice range profile (VRP) in terms of application, easiness to administer the test, and duration needed to complete the test. There is a need for a simple tool to measure the physiologic limit of phonatory system in Hindi for Indian population.

Objective: The objectives of the present study were to (1) measure SRP in persons with hyperfunctional voice disorders and to compare the findings with persons with normal voice in both male and female groups and (2) find whether SRP measure can be used to differentiate between the hyperfunctional voice disorder and normal voice.

Design: A case-controlled observational study.

Setting: The study was conducted at speech and hearing unit at the Postgraduate Institute of Medical Education and Research, Chandigarh. The data were collected during 6 months between January and June 2019.

Patients: The subject group $(n=70)$ comprised 35 male and 35 female participants with hyperfunctional voice disorders, while the control group $(n=70)$ comprised age- and gender-matched participants with normal voice quality.

Measurements: After the videolaryngostroboscopy examination, SRP was obtained using the VRP module in Computerized Speech Lab software from Pentax Medical. The parameters analyzed were the lowest frequency $\left(F_{\min ^{\prime}}, \mathrm{Hz}\right)$, highest frequency $\left(F_{\max }, \mathrm{Hz}\right)$, minimum intensity $\left(I_{\text {min }}, \mathrm{dB}\right.$ $\mathrm{SPL}-$ sound pressure level), and maximum intensity $\left(I_{\max } \mathrm{dB} S \mathrm{SL}\right)$.

Results: The SRP values were compared between the two groups using Mann-Whitney $U$ test. A significant difference was found between the subject group and the control group in mean values of minimum frequency and maximum frequency in female groups. In male groups, significant difference was seen in values of minimum frequency, maximum frequency, $I_{\text {max }}$ as well as intensity range. Subject group with hyperfunctional voice disorder had significantly lower values $(p<0.05)$.

Limitations: The number of subjects is less. There is a need to perform SRP in a larger population and across various voice disorders. Effect of smoking habit was not considered in the study. Also, it is difficult to measure $F_{\max }$ especially in early post-phonosurgery assessment.

Conclusion: Our study shows that SRP can be used clinically to differentiate the hyperfunctional voice disorders from normal voice in both male and female groups.

Keywords: Frequency, Hoarseness, Hyperfunctional, Intensity, Larynx, Nodule, Objective voice assessment, Voice range profile.

International Journal of Phonosurgery \& Laryngology (2020): 10.5005/jp-journals-10023-1177
\end{abstract}

\section{INTRODUCTION}

\section{Background/Rationale}

Assessment of voice involves both subjective and objective tests. The subjective tests are mainly carried out by using different questionnaires or scales as well as by subjective judgment by the clinician. The objective measures involve the use of different software and instruments to assess different aspects of voice. These tests are mainly carried out while the patient is phonating and may involve both habitual vocal performance and maximum phonation tasks. Habitual voice performance is related to how the patient typically uses his or her voice.

In maximum phonation tasks, minimum and maximum fundamental frequencies and intensity are measured, which assess the physiologic limit of voice system. Maximum phonation task measures phonetogram. A phonetogram is a graphic that evaluates the voice frequency-intensity profile. ${ }^{1}$ Some of these usages of the phonetograms include (a) obtaining information on the voice potentials of individuals, (b) studying the effects of a
${ }^{1-5}$ Department of ENT, Postgraduate Institute of Medical Education and Research, Chandigarh, India

Corresponding Author: Noorain Alam, Department of ENT, Postgraduate Institute of Medical Education and Research, Chandigarh, India, Phone: +91 9033747078, e-mail: noorain.aslp@gmail.com

How to cite this article: Alam N, Munjal S, Kumar R, et al. Application of Speech Range Profile in Hindi in Hyperfunctional Voice Disorders: A Case-controlled Observational Study. Int J Phonosurg Laryngol 2020;10(1):18-22.

Source of support: Nil

Conflict of interest: None

given treatment or surgical intervention, and (c) comparing data between the selected groups. ${ }^{2}$

$\mathrm{Hacki}^{3}$ reported reduced voice profile sizes in singing, speaking (SV), and shouting voices (ShV) in most of the dysphonic persons. In another study, values for three granuloma patients differed 2 
standard deviation (SD) or more from the values of the persons with normal voice. $^{4}$

Phonetograms are studied in two groups as "speech range profile (SRP)" to determine the profile of speech voice and as "voice range profile (VRP)" to determine vocal capacity. Speech range profile is defined as the graphical plot of an individual's frequency-intensity interactions occurring during connected speech production. ${ }^{5}$ It is an objective test to assess the physiologic limit of the voice in terms of intensity and frequency, which may be used in place of voice range profile which is measured using continuous phonation task. As speech stimuli are a better method to assess the functional limit of voice, SRP has an advantage over VRP in terms of application, easiness to administer the test, and the duration needed to complete the test. A study ${ }^{4}$ found the total VRP recording time varied between 17:43 and 27:05 minutes, while the time taken to measure SRP recording varied between 0:52 and 1:12 minutes for the patients. In a recent study, SRP measures were compared between pre-and post-therapy in puberphonia patients, and a statistically significant difference was observed between the F0 and MinF0 values before and after therapy $(p<0.001){ }^{6}$

As the VRP test is time taking and very difficult to obtain from the nonsingers, there is a need for a simple tool to measure the physiologic limit of the phonatory system in Hindi for the Indian population.

\section{Objectives}

Our primary objectives were to (1) measure SRP in persons with hyperfunctional voice disorders and compare the findings with persons with a normal voice in both male and female groups and (2) find whether SRP measure can be used to differentiate between the hyperfunctional voice disorder and normal voice.

\section{Materials and Methods}

\section{Study Design}

We used a case-controlled observational study. The SRP was measured in a group of persons with hyperfunctional voice disorders (subject group) as well as in a number and gender-matched persons with normal voice (control group). We analyzed the data and compared the findings between the genders in both the groups.

\section{Setting}

The study was conducted at the speech and hearing unit at the Postgraduate Institute of Medical Education and Research, Chandigarh. The data were collected for a period of 6 months between January and June 2019. The subject group was referred from the ear, nose and throat (ENT) Department, while the control group comprised students and staff of the organization.

\section{Participants}

Two groups of participants in the age range of $18-50$ years were enrolled. All the participants had normal hearing (hearing thresholds from 250 to $8 \mathrm{kHz} \leq 25 \mathrm{~dB} \mathrm{HL}$ ). The subject group comprised 70 participants ( 35 males and 35 females) with hyperfunctional voice disorders. Participants of the subject group were referred from the ENT Department. All the participants underwent a videolaryngostroboscopy examination. The cause of hyperfunctional voice disorder was ascertained using videolaryngostroboscopy assessment by the ENT specialist. Participants having any history of laryngeal surgery, previous speech therapy, malignant or laryngeal lesions, hormonal voice disorders, and spasmodic or psychogenic voice disorders were excluded from the study. The control group comprised age- and gender-matched 70 participants with normal voice quality. Participants did not have any psychological or neurological conditions.

\section{Variables}

Only persons with hyperfunctional voice disorders were included in the subject group and those with neurogenic or psychogenic voice disorders were excluded, as the measures could be different in these voice disorders. The enrolled participants had never undergone any laryngeal surgery or radiation treatment.

\section{Data Sources/Measurement}

The SRP was obtained using the VRP module in Computerized Speech Lab software from Pentax Medical. The SRP included a recording of both SV and ShV. The SV was recorded by asking the participants to read aloud twice 20 sentences in Hindi (adapted from D'alatri and Marchese) ${ }^{7}$ at their most comfortable pitch and loudness as in daily conversation. The sentences contained different suprasegmentals such as interrogative, exclamatory, affirmative, and different feelings like happiness, sadness, and disbelief. The ShV was obtained by asking patients to say twice/ehi/as loud as they could. The participant was asked to imagine that he/she was in a market with a lot of traffic noise and he/she had to call someone who was standing far. The procedure to obtain the SRP required an average of 10 minutes for each participant. Participants were allowed to practice two to three times before actual recording. The parameters analyzed in the SRP were the lowest frequency $\left(F_{\text {min }}, \mathrm{Hz}\right)$, highest frequency $\left(F_{\text {max }}, \mathrm{Hz}\right)$, frequency range $\left(F_{\text {range }}, \mathrm{Hz}\right)$, minimum intensity $\left(I_{\text {min }^{\prime}}, \mathrm{dBSPL}\right)$, maximum intensity $\left(I_{\text {max }}(\mathrm{dBSPL})\right.$, and intensity range ( $\left.I_{\text {range }}, \mathrm{dB} S \mathrm{SP}\right)$.

\section{Bias}

To avoid clinician's bias, the clinicians were not shown the videolaryngostroboscopy findings of any participant during the SRP measurement as well as data analysis. None of the participants had attended voice therapy before the assessment.

\section{Study Size}

The number of cases with hyperfunctional voice disorder in the ENT Department during the study period determined the sample size.

\section{Quantitative Variables}

The frequency and intensity measures were collected and compared between the two groups. The measures were compared within the same gender only, i.e., measurement of male participants with hyperfunctional voice disorder was compared to those of male participants in the control group and the same for the female participants.

\section{Statistical Methods}

As data were not normally distributed, statistical analysis was carried out using the Mann-Whitney $U$ test to compare the differences between the two groups. The results were analyzed and compared between the subject and control groups. A $p$ value $<0.05$ was considered to be significant.

\section{Results}

\section{Participants}

Two groups, i.e., subject and control groups were taken, each comprising 70 ( 35 males and 35 females) participants. The subject group had hyperfunctional voice disorder, while the control group had normal voice quality. 


\section{Descriptive Data}

In the subject group, the average age of male participants was 36.7 (SD 8.08) years, while for female participants it was 36.8 (standard deviation, SD 8.34) years. In the control group, the average age of male participants was 34 (SD 3.9) years and for female participants, it was 30 (SD 5.9) years.

\section{Outcome Data}

The number of participants was equally distributed, i.e., 35 male and 35 female participants in the subject group as well as in the control group. The videolaryngostroboscopy findings showed that in the female subject group, participants had nodule (23), polyp (5), congested vocal cords (3), contact ulcer (3), and leukoplakia (1). While in the male subject group, participants had nodule (20), polyp (12), and congested vocal cords (3). The videolaryngostroboscopy findings were normal for control group participants.

All participants could perform the SRP procedure. The SRP was performed using the method described in the methods section. Minimum, maximum, and the range values for both frequency (in $\mathrm{Hz}$ ) and intensity (in dB SPL) were measured.

Figures 1 to 4 show the SRP of hyperfunctional voice disorder and normal vocal individuals in one male and one female participants, respectively.

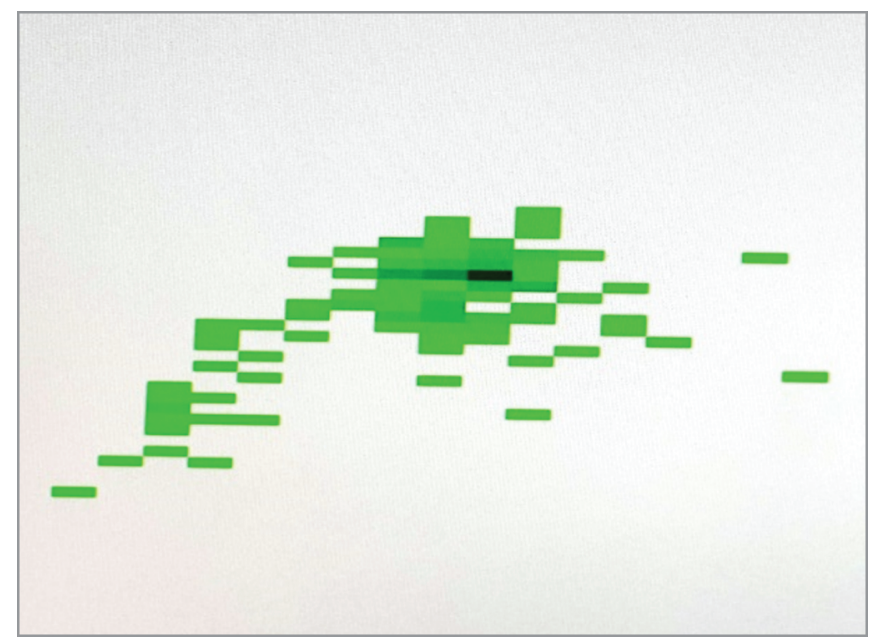

Fig. 1: Speech range profile graph in a 28-year-old male with left hemorrhagic vocal cord polyp

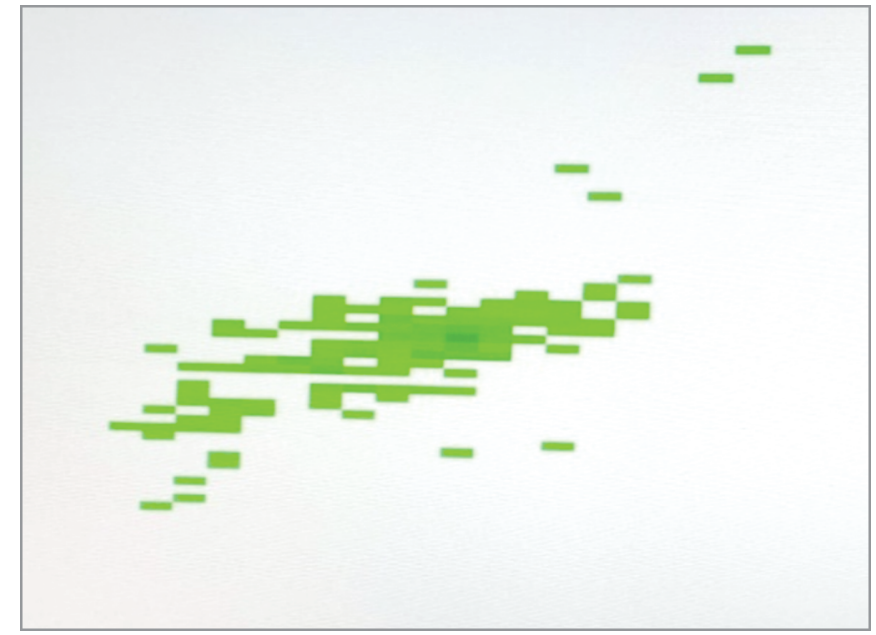

Fig. 3: Speech range profile graph in a 23-year-old male with normal voice quality

\section{Main Results \\ Comparison of Female Participants}

There was a significant difference between the subject and control groups in mean values of minimum frequency, maximum frequency, and frequency range. The mean value of minimum frequency in the subject group was 118.21 (SD 45.33) Hz which was significantly lower than the control group's 147.69 (SD 53.32) Hz $(p<0.05)$. The mean value of maximum frequency in the subject group was 303.33 (SD 81.93) Hz which was significantly lower than the control group's 405.51 (SD 63.77) $\mathrm{Hz}(p<0.05)$.The mean frequency range in the subject group was 56.8 (SD 7.4) Hz which was significantly lower than the control group's $62.37(6.07) \mathrm{Hz}(p<0.05)$. The mean value of $I_{\text {min }}$ in the subject group was 56.8 (7.4) dB SPL which was significantly lower than the control group's 62.37 (6.07) dB SPL $(p<0.05)$. The mean value of $I_{\max }$ in the subject group was 89.74 (6.21) dB SPL which was significantly lower than the control group's 93.46 (SD 6.91) dB SPL $(p<0.05)$. No significant difference was observed in the / range value between both the groups (Fig. 5).

\section{Comparison of Male Participants}

As shown in Table 1 and Figure 6, a significant difference was seen in the values of minimum, maximum frequency value, $I_{\max }$ and the intensity range between the male subject and male control

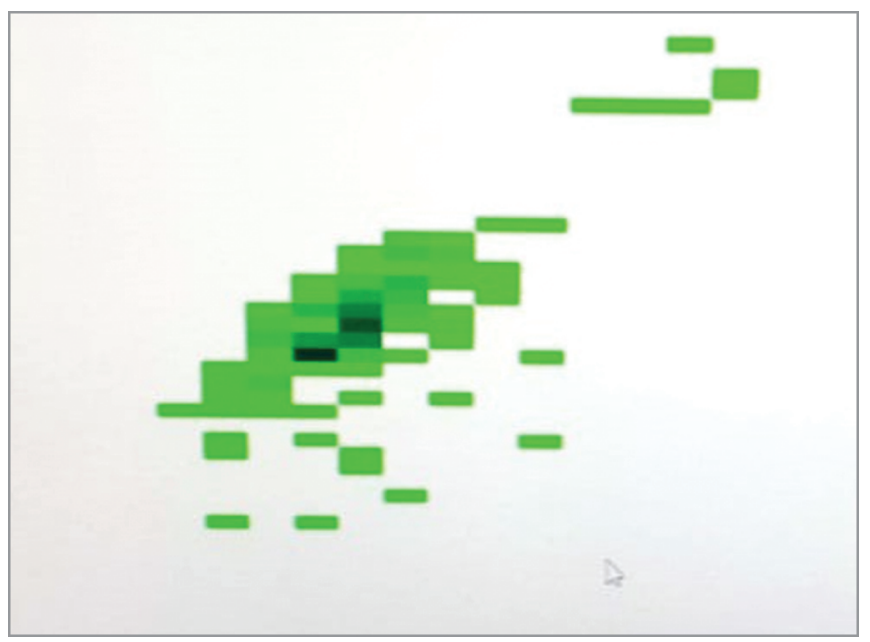

Fig. 2: Speech range profile graph in a 33-year-old female patient with bilateral vocal nodule

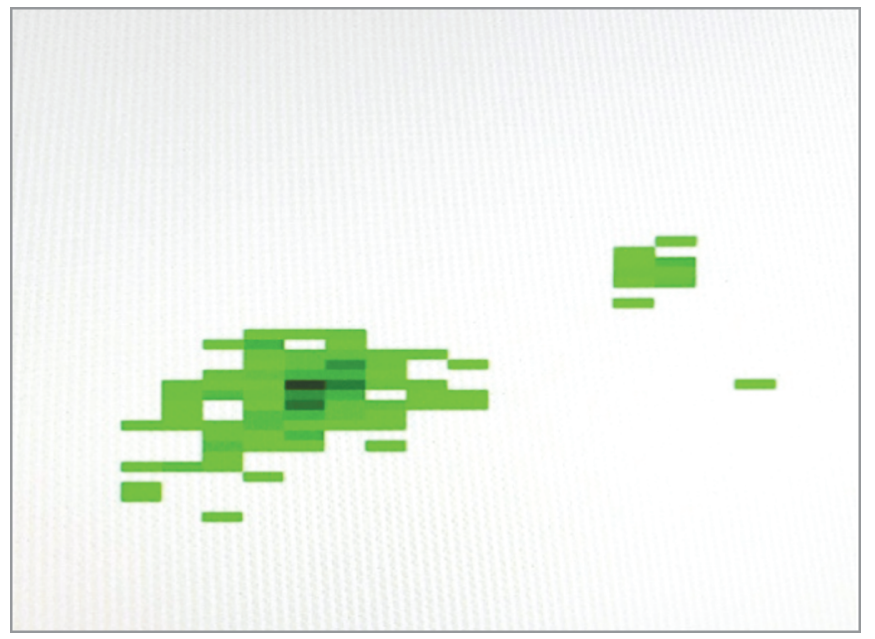

Fig. 4: Speech range profile graph in a 22-year-old female with normal voice quality 
groups. The subject group with hyperfunctional voice disorder had significantly lower values $(p<0.05)$. The mean value of minimum frequency in the subject group was 92.45 (SD 24.06) $\mathrm{Hz}$ which was significantly lower than the control group's 106.73 (SD 21.58) Hz $(p<0.05)$. The mean value of maximum frequency in the subject group was 261.4 (SD 75.87) Hz which was significantly lower than the control group's 305.29 (SD 76.42) Hz $(p<0.05)$. The mean value of $I_{\text {max }}$ in the subject group was 93.57 (SD 11.68) dB SPL which was significantly lower than that of the control group 98.33 (SD 8.62) dB SPL $(p<0.05)$. The mean value of the intensity range in the subject group was 33.97 (SD 14.16) dB SPL which was significantly lower than that of control group 39.77 (SD 9.53) dB SPL ( $p<0.05)$. The value of $I_{\min }$ was 59.37 (SD 6.6) dB SPL in the subject group which was marginally more than that of the control group which had $I_{\min }$ value of 58.36 (SD 5.48) dB SPL.

\section{Discussion}

\section{Key Results}

The present study was carried out to find the SRP values of persons with hyperfunctional voice disorders and to find whether the SRP may be used to differentiate the hyperfunctional voice disorders and normal voice quality in male and female participants. The SRP

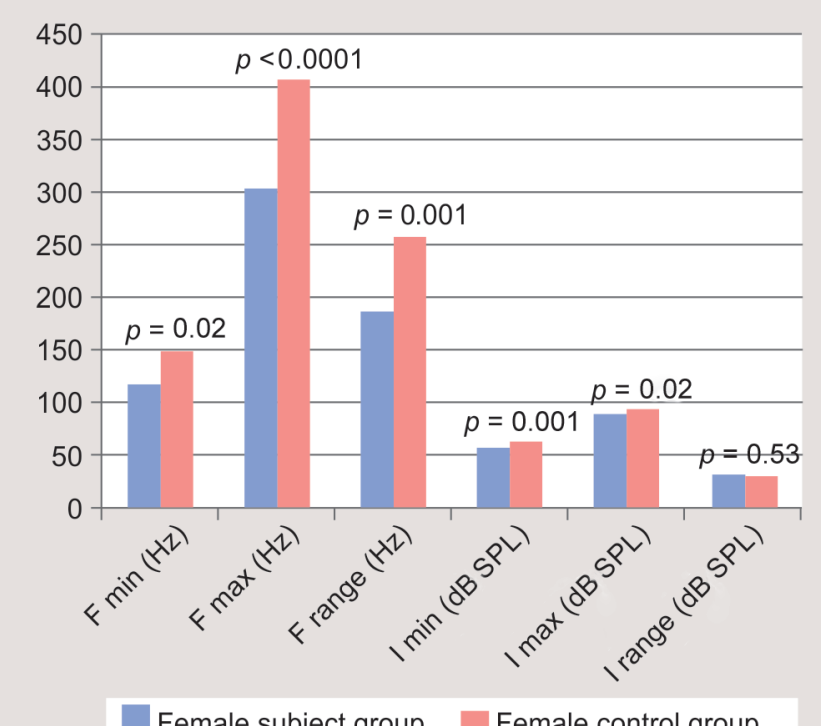

Female subject group Female control group

Fig. 5: Comparison of SRP measures (with $p$ values) between female subjects with hyperfunctional voice disorder and female control group was measured for both the subject and control groups and the values were compared. There was significantly reduced mean $F_{\text {min }}$ and $F_{\text {max }}, F_{\text {range, }} I_{\text {min }}$ and $I_{\text {max }}(p<0.05)$ in the female subject group in comparison to the control female group (Fig. 5). Similarly, there was significantly reduced $F_{\text {min }} F_{\text {max }}, I_{\text {max }}$, and $I_{\text {range }}$ in the male subject group in comparison to the control male group (Fig. 6).

\section{Limitations}

The number of subjects is less in the present study. There is a need to perform SRP in a larger population and across various voice disorders to generalize our findings. Also, there is a need to compare the changes in SRP measures post voice therapy protocol and phonosurgery to find whether these measures could quantify the efficacy of these interventions. A confounding factor, i.e., smoking habit, was not considered in the present study. A limitation of SRP measurement is the difficulty in measuring the $F_{\text {max }}$ in early post phonosurgery assessment.

\section{Interpretation}

A hyperfunctional voice is produced with abnormally stiff vocal folds often in combination with increased subglottal air pressure and abnormally high vocal fold closing velocities. ${ }^{8}$ Abnormal SRP findings may be due to the increase in vocal fold mass and

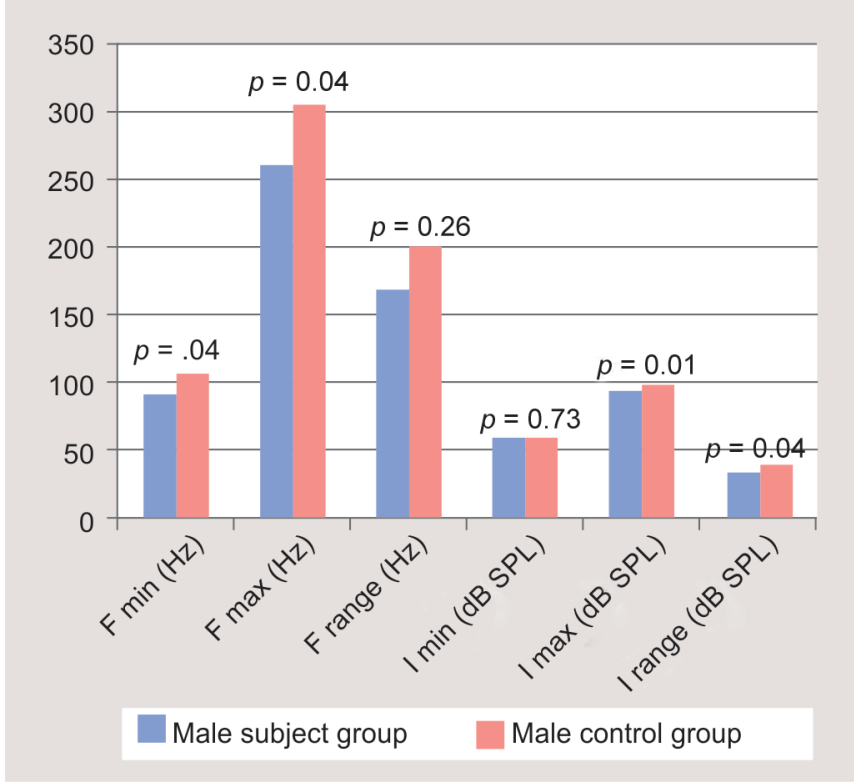

Fig. 6: Comparison of SRP measures (with $p$ values) between male subjects with hyperfunctional voice disorder and male control group

Table 1: Speech range profile measures in male and female participants in subject and control groups

\begin{tabular}{lllllll}
\hline Participants & $F_{\min }(\mathrm{Hz})$ & $F_{\max }(\mathrm{Hz})$ & $F_{\text {range }}(\mathrm{Hz})$ & $I_{\min }(d B S P L)$ & $I_{\max }(d B S P L)$ & $I_{\text {range }}(d B S P L)$ \\
\hline $\begin{array}{l}\text { Female subject } \\
\text { group }\end{array}$ & $118.21(45.33)$ & $303.33(81.93)$ & $185.91(85.91)$ & $56.8(7.4)$ & $89.74(6.21)$ & $32.94(10.9)$ \\
$\begin{array}{l}\text { Female control } \\
\text { group }\end{array}$ & $147.69(53.32)$ & $405.51(63.77)$ & $257.23(81.5)$ & $62.37(6.07)$ & $93.46(6.91)$ & $31.28(8.16)$ \\
$\begin{array}{l}Z(p) \\
\text { Male subject }\end{array}$ & $2.29(0.02)$ & $4.94(<0.0001)$ & $3.16(0.001)$ & $3.21(0.001)$ & $2.40(0.02)$ & $0.622(0.53)$ \\
group & $92.45(24.06)$ & $261.4(75.87)$ & $169.03(80.57)$ & $59.37(6.6)$ & $93.57(11.68)$ & $33.97(14.16)$ \\
$\begin{array}{l}\text { Male control } \\
\text { group }\end{array}$ & $106.73(21.58)$ & $305.29(76.42)$ & $199.41(82.62)$ & $58.56(5.48)$ & $98.33(8.62)$ & $39.77(9.53)$ \\
$Z(p)$ & $2.02(0.04)$ & $2.04(0.04)$ & $1.12(0.26)$ & $-0.35(0.73)$ & $2.52(0.01)$ & $2.05(0.04)$ \\
\hline
\end{tabular}


stiffness associated with the presence of laryngeal pathologies in participants with hyperfunctional voice disorders that prevented stretching of the vocal folds to phonate at both very high and very low frequencies leading to decreased $F_{\min }$ and $F_{\max }$ values (in male and female subject groups) ${ }^{9}$ as well as $I_{\max }$ and $I_{\text {range }}$ values (in the male subject group) which was evident in both male and female groups with hyperfunctional voice disorders.

However, there was no significant difference between the mean $I_{\min }$ of the hyperfunctional male group and the control group. The reading task for measuring SRP did not require participants to push to their physiological vocal limits for the production of the lowest speaking loudness.

This is the first study where both female and male groups have been enrolled and findings were compared. Ma et al. ${ }^{5}$ studied the SRP and VRP in dysphonic and vocally healthy female groups and found there was a significant difference in the measurement of $F_{\text {max }}$ $I_{\text {max }}$ and $I_{\text {min }}$ between both groups similar to our study. However, $I_{\min }$ was elevated in the dysphonic group which was seen only in the male group in the present study.

\section{Generalizability}

The present findings show that SRP can be used clinically to differentiate hyperfunctional voice disorders from a normal voice. Due to the shorter administration time (about 10 minutes) and simple procedure involved, the SRP can be used as an objective tool to screen hyperfunctional voice disorders along with other measurements, which adds information about the physiologic limits of the phonatory system. There is a need to perform SRP in a larger clinical population to generalize the findings.

\section{List of SEnTENCES USED for SRP MEASUREMENT}

1. क्या समय हुआ है? (What time is it?)

2. आपका नाम क्या है? (What's your name?)

3. बाहर मौसम कैसा है? (How's the weather outside?)

4. क्या आपको फ़िल्म पसंद आयी? (Did you like the movie?)

5. क्या आप पार्टी में आओगे? (You will come to the party?)

6. खाने में क्या है? (What's for dinner?)

7. क्या तुमने इतनी मेहनत की? (You worked so hard?)

8. चले जाओ! मै तुम्हारी बदतमीज़ी से परेशान हो चुका / चुकी हूँ। (Go away. I'm fed up with you.)

9. देखो! मै अब अकेला / अकेली नहीं हूँ। (Look I'm no longer alone!)
10. मुझे माफ़ कर दो! (Please forgive me!)

11. बस करो! मै ये अब और नहीं सह सकता/सकती! (Stop!l can't take it anymore!)

12. क्या सुहाना सफर है! (What a pleasant journey!)

13. मुझे रहम नहीं, इन्साफ चाहिए। (I want justice, not mercy!)

14. बस! मुझे तुम्हारी बात नही सुननी। (Stop it! I do not want to listen to you)

15. मुझे ये बहुत पसंद है! क्या तुम मुझे दे सकते हो? (I like it very much! Will you give it to me?)

16. इस बेकार चीज के लिए मुझे अपना पसीना नहीं बहाना। (I do not want to sweat, it's useless)

17. इधर आओ। (Come here!)

18. क्या तुम अब मेरी बात सुनोगे? (Will you listen to me now?)

19. नहीं! मै इन शर्तों को नहीं मानता। (No, I don't agree with these conditions)

20. यह संभव नहीं हो सकता! (That's not possible!)

\section{References}

1. Sataloff RT. Professional Voice the Science and Art of Clinical Care. San Diego: Singular Publishing Group; 1997.

2. LeBorgne WD, Weinrich BD. Phonetogram changes for trained singers over a nine-month period of vocal training. J Voice 2002;16(1):37-43. DOI: 10.1016/S0892-1997(02)00070-X.

3. Hacki T. Comparative speaking, shouting and singing voice range profile measurement: physiological and pathological aspects. Logoped Phoniatr Vocol 1996;21(3-4):123-129. DOI: 10.3109/14015439609098879.

4. Hallin $A E$, Frost $K$, Holmberg EB, et al. Voice and speech range profiles and voice handicap index for males-methodological issues and data. Logoped Phoniatr Vocol 2012;37(2):47-61. DOI: 10.3109/14015439.2011.607469.

5. Ma E, Robertson J, Radford C, et al. Reliability of speaking and maximum voice range measures in screening for dysphonia. J Voice 2007;21(4):397-406. DOI: 10.1016/j.jvoice.2006.03.004.

6. Gokdogan C, Gokdogan O, Tutar H, et al. Speech range profile (SRP) findings before and after mutational falsetto (puberphonia). J Voice 2016;30(4):448-451. DOI: 10.1016/j.jvoice.2015.05.014.

7. D'alatri L, Marchese MR. The speech range profile (SRP): an easy and useful tool to assess vocal limits. Acta OtorhinoLaryngol Ital 2014;34(4):253-258.

8. Hillman RE, Holmberg EB, Perkell JS, et al. Phonatory function associated with hyperfunctionally related vocal fold lesions. J Voice 1990;4(1):52-63. DOI: 10.1016/S0892-1997(05)80082-7.

9. Heylen L, Wuyts FL, Mertens F, et al. Normative voice range profile of male and female professional voice users. J Voice 2002;16(1):1-7. DOI: 10.1016/S0892-1997(02)00065-6. 